\title{
Status, directions and priorities of reindeer husbandry research in Sweden
}

\author{
Öje Danell

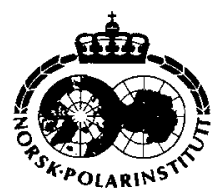

\begin{abstract}
Emerging out of small-scale reindeer farming, large-scale reindeer husbandry in Sweden and Norway was developed to counteract resource scarcity caused by depleted wild reindeer numbers and human population growth above what the former subsistence economy could sustain. Current numbers of reindeer are likely lower and fluctuate less than before wild reindeer were depleted and reindeer husbandry started on a large scale. Productivity is about $7-8 \mathrm{~kg}$ of meat per head in winter stock. Current problems arise from a multitude of circumstances, some of them related to the problems of practising a subsistence type of living in close connection with a modern industrialized society. Problems include: low production, typical for harsh conditions and use of an unimproved animal stock; the inability to support a modern standard of living solely from reindeer; the collective access to grazing grounds which makes internal management difficult; unclear legal rights resulting in conflicting interests with other land users and formal owners; and the relatively low number of people directly involved in reindeer husbandry. Possible long-term consequences are marginalization and the loss of land use rights, with negative consequences for the Saami as an indigenous people. Reindeer husbandry research addresses these problems by integrating human-ecological and socio-economic aspects with traditional natural science orientated research on reindeer husbandry problems. This research is funded by a multitude of sources. Independently of this, research is conducted on Saami life and culture in relation to reindeer husbandry at various universities, especially within social sciences and arts.
\end{abstract}

Danell, Dept. of Animal Breeding and Genetics, Reindeer Husbandry Unit, Box 7023, SE-750 O7 Uppsala, Sweden.

Present problems in Swedish reindeer husbandry have a background in changes in the past as well as in modern economic and social developments in the region and the country. Originally, the smallscale intensive management of tame reindeer was part of an economy based on the multifaceted use of natural resources and included hunting and fishing. A dramatic change in the subsistence economy occurred during the Middle Ages due to human population growth and heavy taxation imposed by the state (Kvenangen 1996; Lundholm et al. 1996). This led to depletion of both domestic and wild reindeer populations. The subsistence problems were solved by differentiation into specialized livelihoods like fishery, agriculture and nomadic reindeer husbandry. The domesticated reindeer populations of today are considered to originate mainly from the small privately owned tame flocks which were expanded as a substitute for rapidly declining and ultimately extinct wild herds. The present large-scale type of reindeer husbandry is consequently not more than $300-400$ years old, but was established under full legal recognition and protection by the state. As a result of this development, reindeer husbandry rarely met more than minimum subsistence requirements for those involved in it. Today we recognize this situation as a serious socio-economic problem the industry has inherited.

\section{Background to the present situation}

During this century reindeer husbandry has devel- 


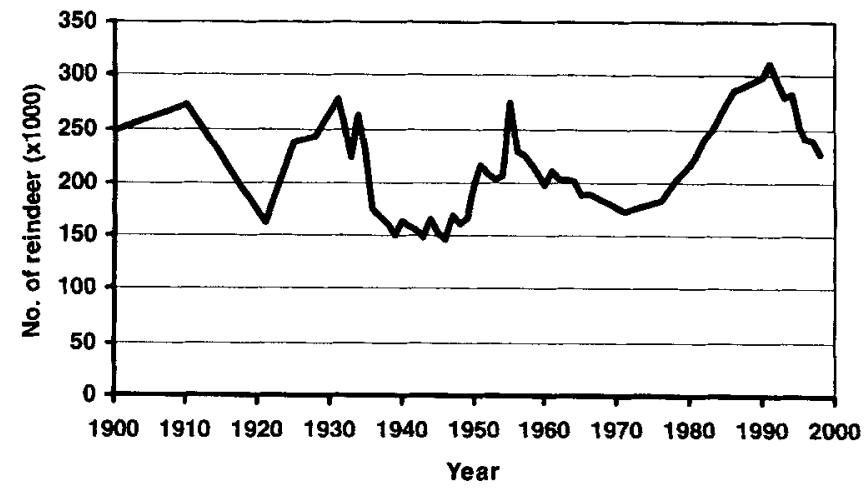

Fig. 1. Size of winter stock of reindeer in Sweden during the 20th century according to various official sources.

oped into an extensive type of transhumance where privately owned flocks are merged into large herds and mainly collectively herded during the snow-free season, and then broken up into smaller flocks that are more intensively herded during winter. Continually down-regulated by the harvest, the population size fluctuates less than a wild reindeer population might do under similar ecological conditions. As long as recorded, the population size has quite regularly been around $225000 \pm 50000$ animals in the winter stock (Fig. 1). Between 30000 and 90000 animals have been slaughtered annually during the last 30 years. Excluding what is consumed by the household, the normal productivity level is $7-8 \mathrm{~kg}$ per animal in winter stock under conditions where adult females weigh around $70 \mathrm{~kg}$ in late autumn. The harvest comprises around $40 \%$ calves and $25-35 \%$ adults of each sex. Productivity has been both higher and lower during periods when animal numbers have been intentionally reduced or declined due to adverse conditions. The population is currently decreasing from a somewhat higher peak (more than 300000 head) in the early 1990s, partly as a result of the problems following the Chernobyl accident. Current productivity is $5.4 \mathrm{~kg}$ carcass per head (figures from 1998).

Grazing resources are managed by 51 herding communities ("Saami villages") on a common property basis, with the well-known management difficulties connected to the use of common access resources. Access to grazing lands has decreased significantly during the 20th century. Reasons are a loss of traditional summer ranges towards and along the Atlantic coast (now about $2.7 \%$ of the total grazing area) as a result of a gradual closure of the Swedish-Norwegian border for reindeer migration, and expanding industrial forestry and other regional and national economic interests in the winter grazing areas during many decades. Pressure from tourism and other recreational interests has increased considerably during the last few decades, especially in the present summer grazing areas. Conflicts between reindeer industry and formal land owners has escalated in the winter areas due to the lack of legally defined extents of the grazing rights. These rights are now increasingly challenged by the state and private land owners and brought to court trials for resolution. This may partly be an effect of Sweden trying to come to terms with the ratification of the ILO Convention no. 169 on Indigenous and Tribal Peoples in Independent Countries.

A growing strain on the reindeer industry is caused by national commitments to restore viable populations of brown bear, lynx, wolverine, wolf and golden eagle. These predator populations, with the exception of wolves, are largely located in the reindeer herding areas, with the semi-domesticated reindeer being a major food resource. Predation takes away about a third or more of the surplus available for harvest; consumption by predators may increase further when long-term proposals for predator populations are realized.

Especially after the 1950 s, reindeer herding Saami have been rapidly integrated into the greater Swedish society. The mechanization of reindeer management stems from such social causes as increased sedentarization (e.g. Nilsen \& Mosli 1994) as well as from manpower shortages. Economic returns to the herders are low. To meet the costs of living in a modern society, reindeer herding families depend on some members taking up other occupations. In 1993, reindeer husbandry contributed on average $20 \%$ of the family income, ranging from considerably less than $10 \%$ in the 
county of Norrbotten (on average 170 reindeer per enterprise) to nearly $50 \%$ in the counties of Västerbotten and Jämtland (both with more than 400 reindeer/enterprise) (Riksdagens Revisorer 1996). Considering recent declines in animal stock, the current contribution from herding is likely less. Adding to this picture, out of about 1720000 Saami in Sweden, only about 1900 people are active herding members/reindeer owners, with about 1800 more involved as so-called "additional members" in the herding communities. These numbers exclude about 1000 non-Saami reindeer owners among farmers/land owners in the eastern part of the county of Norrbotten, each of them owning a maximum of 30 reindeer in so-called concession herding communities.

In spite of low profitability, there is high interest within Saami society to "have a foot" in reindeer herding. The wish to retain a share in Saami land use rights probably plays a role in this: legal rights to reindeer herding, hunting, fishing and some use of forest products are connected to membership in a "Saami village", the latter being both a land area and an economic association of reindeer owners/ herders. Also quite significant is the high symbolic value the reindeer industry has for Saami identity and the importance of reindeer herding for the preservation of Saami culture and language.

Reindeer husbandry is also fairly important in the regional economy beyond the Saami community. In the Jokkmokk Municipality in the country of Norrbotten, for example, reindeer husbandry is estimated to account indirectly for about twice as much employment as it directly employs, or $15 \%$ of the total occupancy in the municipality (Ingrid Inga, Jokkmokk Municipality, pers. comm. 1998). To this may be added employment in trading and services demanded by people involved in the reindeer industry and in the recreation and tourist industry for which reindeer husbandry is one of the attractions. These contributions from the reindeer industry to the regional economies have not been properly investigated and are generally not recognized to their full extent.

\section{A crisis scenario}

Thus the problems today are of a socio-economic and legal character as much as they stem from natural resource limitations. There are both acute and long-term dimensions to this.
There are several adverse, concurrent trends which risk the short-term survival of reindeer herding. Reindeer numbers, and the harvest, are declining according to a predictable pattern, but this time from a higher peak than before. Forage resources might be more degraded than on previous occasions due to both the higher recent peak in reindeer numbers and a continuing reduction of available grazing land. There may also be an accumulated decline in ground and arboreal lichen resources as a consequence of more intensive forestry operations during the past 30-40 years, now making itself noticed. The reindeer husbandry may therefore be increasingly vulnerable to variations in weather conditions. There is also the increasing pressure from predators, legal insecurity and continuously expanding external interests. The combination may result in a reduction in the number of people in the industry due to economic and psycho-social reasons. This development may solve some structural problems in the industry, such as low numbers of reindeer per enterprise, but management will become more difficult and costly for those remaining in business.

A growing problem is that the low productivity of reindeer husbandry has difficulty providing the economic resources to support the needs of modern life. As considerably more than food and a minimum of other material resources for living are needed, either productivity or herd sizes must be raised to increase income. This is generally not possible, so the limited, partial contribution of reindeer husbandry to family livelihoods must be accepted. The future "economic" strength of reindeer husbandry therefore depends on what non-material values reindeer husbandry can provide. If these cannot be named and valued, the economic and social motivation for reindeer husbandry will continue to weaken.

The possible long-term scenario of a continued crisis along these lines is a marginalization of reindeer husbandry in several respects. The importance of the reindeer industry for the regional economy in general may decline in proportion to a decline in occupation within the industry. It seems that many of the difficulties which reindeer herders face in competing with other natural resource users arise from that reindeer husbandry is a discriminating but extensive user of land, with a comparably low productivity and economic turnover if reckoned only according to market values. If so, it will be 
even more difficult for a decreasing group of reindeer herders to defend these rights against less discriminating but commercially more aggressive users - unless reindeer herding rights become legally well-established, or reindeer husbandry is acknowledged for its indirect economic contributions as well as its non-market values to the wider Swedish society. Reindeer husbandry may also lose its importance among Saami if herding traditions are practised by an even smaller minority of these indigenous people. The Saami language in Sweden has its principal "refuge" as a working language in reindeer husbandry, but the "conservation by management (or use)" principle might not work if the practitioners of the language in the working life become too few - a development already realized in the southern parts of the Scandinavian reindeer herding area.

\section{Present research priorities and ongoing research}

In Sweden, as in neighbouring countries, previous research linked to the development of reindeer husbandry has largely focused on its biological aspects. These include nutrition and feeding, carcass composition, animal health issues, losses, herd productivity and selection of recruitment animals, impacts of forestry operations on lichen resources and problems caused by the Chernobyl accident. The knowledge achieved has been valuable but we can see that it has not solved the principal problems faced by the industry. Social sciences and humanities research, conducted as individual projects at different universities, has not been well integrated with the natural science research.

To counteract a development in line with the crisis scenario outlined earlier, research efforts clearly need to be truly multi-disciplinary with both natural and social sciences involved. The reindeer husbandry research programme at the Swedish University of Agricultural Sciences has therefore recently been broadened to encompass human-ecological and socio-economic aspects of reindeer husbandry. Deeper knowledge in biological aspects of reindeer husbandry is still considered essential, but knowledge in other disciplines with relevance for reindeer husbandry needs to be developed in parallel and more integrated with the biological research. Moreover, cooperation with ongoing independent research in, for example, sociology and anthropology with relevance for reindeer husbandry needs to be strengthened further.

The reorientation of reindeer husbandry research in Sweden during the last half decade has resulted in a broader network between disciplines and research institutions. The majority of the research is carried out in connection with post-graduate education programmes at the Swedish University of Agricultural Sciences. A close collaboration has been built up with the industry and its branch organization, the Swedish Saami Union, which is a member organization of individual "Saami villages" and local Saami associations. Sources of financing are diverse and include faculty resources, research councils, government and Nordic Council funding, funds for environmental strategic research (MISTRA), and EU funding as well as industry funding in development projects carried out by the industry itself or in partnerships with research organizations. Industry funding usually aims at developing various technical aids, testing and implementing alternative management solutions or improving the competence and skills in the industry, e.g. the use of information technology. The industry is also building up its own research information service as a complement to traditional research information channels.

In brief, reindeer husbandry research now encompasses a wide range of activities and topics:

- Development of the tools and strategies for adaptive management of reindeer pasture resources is becoming a major field of research. It includes improvement of remote sensing aided techniques for identifying, mapping and monitoring habitat resources, the establishment of affordable survey methods for quality assessment and quantification of forage biomass, and the development of calibration tools to facilitate adaptive management strategies as a part of the industry's own planning. Traditional knowledge on pasture use is investigated and contrasted against scientifically proved knowledge in this field.

- Further research on radioactive caesium, still a problem in reindeer pastures, is undertaken to better understand the long-term effects of this contamination.

- Research efforts within animal resource management aim at finding optimum stocking rates, condition levels of animal stock and optimum herd structures to maximize net economic returns. Selective recruitment of calves and culling of adults with the help of production records is 
another possibility already practised to some extent, but strategies and possible drawbacks are under further investigation.

- Supportive feeding and management during late pregnancy and calving, when the gap between females' nutritional requirements and the natural food supply is at its widest, is an example of currently studied potential improvements to husbandry to increase productivity and decrease losses. Feeding techniques in emergency situations are also studied, with particular reference to problems caused by previous starvation. However, feeding is not generally expected to be economically feasible due to the low productivity of reindeer.

- Animal handling techniques have so far been studied mainly from animal welfare and-meat quality perspectives. Product related investigations now focus on the quality of meat from different types of animals and produced under different management systems.

- Research aiming to develop common planning and optimizing strategies for reindeer husbandry, forestry operations and other consumptive and non-consumptive uses of reindeer grazing ranges are being initiated.

- The foundation of the legal rights connected to reindeer husbandry and associated resource uses are studied from a theoretical common property rights perspective to elucidate the principles, or lack of principles, behind the recent development in this area.

- Economic research include analyses of the extent to which individual enterprises can make their own decisions in business matters vs. decisions taken by the herding community. The aim is to understand better the conditions under which reindeer husbandry enterprises work and to stimulate the development of better organizational forms for reindeer industry in general. Resource and business analyses of reindeer husbandry enterprises under various management strategies and competing influences from other users of natural resources have also started.

- The interaction of reindeer husbandry with conflicting interests, such as predator conservation, forestry and recreation, is addressed in several projects now being initiated. The aim is to suggest co-management and co-existence solutions rather than merely to survey the mutual impacts of these interests.

- A large number of projects aiming at organiza- tional, industrial and cultural developments, conducted by the industry or various Saami organizations, should also be mentioned. The total budget of this industry-administrated research and development is about 100 million Swedish krona (ca. 12 million US dollars) for the last four years, of which $50 \%$ is funded via EU programmes.

The research programme needs to be widened further to include studies on interactions and integration of reindeer husbandry with other sectors of the regional economy and society, and on the role of reindeer husbandry for Saami cultural identity and development.

\section{Conclusions}

The current situation has rendered those in the Saami community who are directly dependant on reindeer extremely vulnerable from an economic standpoint. Indirectly, these circumstances also endanger the survival of the Saami culture because of its close connection with reindeer husbandry. Research can be one way to solve problems in this context. Such research needs to be multi-disciplinary, however, integrating natural sciences with social, political and legal sciences. Nevertheless, it is necessary to be realistic about what can be solved by research in the short time available, as the problems which reindeer husbandry faces also partly stem from opinions and political decisions governed by the majority of people. In this respect it is probably a disadvantage that reindeer husbandry is an activity occurring in the midst of a modern society which partly competes for the same resources.

\section{References}

Kvenangen, P. G. 1996: Samernas historia. (History of the Saami.) Jokkmokk: Sameskolstyrelsen.

Lundholm, K. O., Groth, Ö. J. \& Petersson, R. Y. 1996: North Scandinavian history. Luleå.

Nilsen, R. \& Mosli, J. H. 1994: Inn fra vidda. Hushold og okonomisk tilpasning $i$ reindrifta $i$ Guovdageaidnu 1960-93. (In from the plains. Household and economic adaptation in reindeer husbandry in Gouvdageaidnu 1960-93.) NORUT Samfunnsforskning Rapp. SF 17.

Riksdagens Revisorer (Parliamentary Auditors) 1996: Stödet till rennaringen. (The support to the reindeer industry.) Rapp. 1995/96, no. 8 . 